\title{
Gender differences when using sedative music during colonoscopy
}

Ida Björkman, Frida Karlsson, Ann Lundberg and Gunilla Hollman Frisman

\section{Linköping University Post Print}

N.B.: When citing this work, cite the original article.

This is a non-final version of an article published in final form in:

Ida Björkman, Frida Karlsson, Ann Lundberg and Gunilla Hollman Frisman, Gender differences when using sedative music during colonoscopy, 2013, Gastroenterology Nursing, (36), 1, 14-20.

http://dx.doi.org/10.1097/SGA.0b013e31827c4c80

Copyright: Lippincott, Williams \& Wilkins

http://www.lww.com/

Postprint available at: Linköping University Electronic Press

http://urn.kb.se/resolve?urn=urn:nbn:se:liu:diva-89753 


\section{Gender differences when using sedative music during colonoscopy}

Ida Björkman, Frida Karlsson, Ann Lundberg, Gunilla Hollman Frisman

Authors:

Ida Björkman RN, BSc, Department of Surgery, University Hospital, Linköping, Sweden.

Frida Karlsson RN, BSc, Department of Cardiology, University Hospital, Linköping, Sweden.

Ann Lundberg EN, Department of Gastroenterology, University Hospital, Linköping, Sweden.

Gunilla Hollman Frisman, RNT, PhD, Ass Prof, Department of Gastroenterology, University

Hospital, Linköping and Division of Nursing Sciences, Department of Medicine and Health,

Faculty of Health Sciences, Linköping University, Linköping, Sweden.

Corresponding author: Gunilla Hollman Frisman, RNT, PhD, Ass Prof, Division of Nursing

Sciences, Department of Medicine and Health, Faculty of Health Sciences, Linköping University, Linköping, Sweden. Telephone: +46 10103 32115. E-mail: Gunilla.Hollman.Frisman@liu.se

\section{ACKNOWLEDGEMENTS}

Thanks to all participating patients and staff at the colonoscopy unit. The study was supported by the Gastroenterology department at the University Hospital in Linköping, Sweden. 


\section{INTRODUCTION}

Throughout history, music has been used as a nursing intervention to relieve sickness and suffering. Even in the $19^{\text {th }}$ century, Florence Nightingale used music to calm her patients. It is known that music is a unique experience for the individual and may influence breathing, heart rate, blood pressure and the need for oxygen. The choice of music is important, and the response to music is influenced by earlier experience of music as well as by gender, age, culture, mood, and attitude. Consequently, nurses ought to consider the individual's preferred music in order to achieve a good therapeutic effect (Engwall \& Sörensen Duppils, 2009).

Instrumental music having about $60-80$ beats per minute without significant rhythms or beats can be defined as sedative, relaxing music. A rate of beats per minute that mimics the heart rate has previously be found to have the most relaxing effect (Bonny, 1986). Factors such as tempo, volume and genre may have an influence on how the music is perceived by the listener (Vanderboom, 2007). Music acts as a distractor, occupying the mind with something pleasant, and takes the patients' attention away from negative experience and replaces it with encouraging thoughts (Nilsson, 2008). Sedative music may be played either through speakers or earphones. When using earphones the patient may change the volume as he or she likes and outer sounds consequently are reduced (Chan et al., 2003; Harikumar et al., 2006; Smolen et al., 2002; Vanderboom, 2007).

Sedative music is shown to have a beneficial effect on anxiety (Engwall \& Sörensen Duppils, 2009), pain and stress (Nilsson, 2008). In pre-operative settings, relaxing music is reported to reduce pre-operative anxiety to a greater extent than sedative oral pre-medication (Bringman et al., 2009). Furthermore, having children listen to music prior to and during procedures such as lumbar puncture (Nguyen et al., 2010) and when going through day surgery, adults is reported to reduce their anxiety (Nilsson et al., 2009). 
In this study, anxiety was based on the definition expressed by Spiegelberg (1968). He stressed that anxiety is an emotion associated with circumstances that are expected to be threatening. It is based upon previous experience, and may change in intensity over time (Johnson \& Speigelberg, 1968). In health care, anxiety is sometimes related to fear of pain or to experience of the pain itself. Like anxiety, pain is always a subjective feeling but it may be influenced by previous experiences of pain. The International Association for the Study of Pain has defined pain as an unpleasant sensory and emotional experience associated with actual or potential tissue damage, or described in terms of such damage (Mersky \& Bogduk, 1994).

The opposite feeling, i.e. a sense of well-being, refers to a feeling of pleasure which may be experienced on different levels. The concept of well-being is understood in different ways, but based on the hedonic perspective, subjective well-being is composed of the presence of positive mood, the absence of negative mood, and life satisfaction (Carlisle et al., 2009). This feeling is subjective; it emerges within the individual and could be seen as being very close to happiness, meaningfulness, and satisfaction (Keifer, 2008).

There is not yet enough evidence to prove that music has a positive effect on anxiety and wellbeing. This is due to the variety of instruments used in different studies, which makes it difficult to compare results (Engwall \& Sörensen Duppils, 2009; Nilsson, 2008). However, there is evidence that the level of pain and the amount of medical drugs required decrease when patients undergoing surgery or painful procedures are listening to music (Cepeda et al., 2010; Wilson et al., 2008). Colonoscopy is a painful procedure used to diagnose inflammatory bowel diseases or colon cancer. Colon cancer, the fourth leading cause of death among all cancer diagnoses, has a good prognosis if detected early, often through use of colonoscopy (WHO, 2006). The colonoscopy procedure is often experienced as uncomfortable, although normally the procedure causes no complications (Messman \& Barnet, 2006). Many patients' experience colonoscopy as both stressful and painful (Bechtold et al., 2009; Harikumar et al., 2006), which is why it equally important to sustain the 
patients' subjective experience as well as to establish a diagnosis during the procedure. Some patients may feel violated by the situation (Messman \& Barnet, 2006). Due to the patients' vulnerable situation, nurses have a great responsibility to maintain their well-being (Harikumar et al., 2006). Prior to colonoscopy it is important to give sufficient information about the procedure, and use methods to reduce anxiety and pain. Sedative and analgesic drugs are usually offered (Messman \& Barnet, 2006) but there are also non-pharmacological methods available, such as listening to music, which aim to reduce the experience of discomfort during the colonoscopy (Ylinen et al., 2007).

Nevertheless, the benefits of listening to music during colonoscopy are not clearly proven (Cepeda et al., 2010; Wilson et al., 2008), which is why further studies on this subject are needed (Cepeda et al., 2010; Engwall \& Sörensen Duppils, 2009; Nilsson, 2008; Wilson et al., 2008).

\section{AIM}

The purpose of this study was to analyse the effects of sedative music on patients' experience of anxiety, relaxation, well-being, and pain during colonoscopy.

\section{METHODS}

A randomised intervention was performed in an out-patient setting at an endoscopy department in a University hospital in Southern Sweden.

\section{Sample and design}

Patients scheduled for colonoscopy due to either suspected inflammatory bowel disease or colon cancer were asked to participate. Inclusion criteria were that the subjects should be adult outpatients on the waiting list for colonoscopy, over 18 years old, with normal hearing, sight, and ability to read and understand the Swedish language. Patients with dementia were excluded in order to minimise 
the risk of misunderstanding.

An information letter was sent to the patients together with the invitation to attend the endoscopy department. The study information letter included information about the study, and stated that participation was voluntary, that withdrawal from the study was possible whenever the patient wished, and that non-participation would not influence their care. It also guaranteed the confidentiality of data provided, and included a form for informed written consent. Through the informed consent form the patients accepted that information about drug administration during the colonoscopy would be collected.

Calculation of sample size based on power analysis resulted in 60 patients in each group getting a power of $80 \%$ with $\mathrm{p}<0.05$. Thus the nurses who worked at the endoscopy department collected data from 120 patients. The nurses randomized the patients through sealed envelopes before the intervention. Before the endoscopy, after informed consent was provided, the nurses drew an envelope from the previously randomly mixed envelopes consisting of an equal number of both allocations. The patients received an envelope including information about which group they were assigned to - the intervention or the control group - as well as a questionnaire. The patients were instructed to answer the items on anxiety while waiting for the colonoscopy to start, as a baseline measure. A nurse instructed patients in the intervention group on how to listen to the music when the patient was on the colonoscopy table. The music was played during the whole procedure until the physician ended the colonoscopy. The control group received the usual care with drugs administered when needed. The nurse filled out a medication list if drugs were administered during the colonoscopy and put this in an envelope along with the questionnaire that the patient had filled out after the colonoscopy, just before discharge. The envelope was then sealed.

\section{Intervention}

The involved staff, nurses, enrolled nurses, and physicians received verbal and written information about the study. All patients in the intervention group listened to sedative instrumental music with a 
slow tempo, with 60-80 beats/minute, which had been reported to be calming and relaxing (MilukKolasa et al., 1996; Miluk-Kolasa et al., 1994). The music was played on a CD player with earphones so the patients would not be disturbed by any other sounds and the physician and the nurses would not be disturbed by the music. The patients could control the volume themselves.

\section{Measurements}

All participants answered the same questionnaires, irrespective of whether they were in the intervention or the control group. The questionnaire contained questions that were developed for this study, regarding demographic variables such as gender, age, and previous experience of colonoscopy. Age was divided into five different groups, 18-30 years, 31-50 years, 51-65 years, 6680 years and $>80$ years. The intervention group was also asked to answer questions regarding their desire to listen to music again if undergoing a new colonoscopy, and in that case, if they would then want to choose the music themselves.

The questionnaire contained the State Trait Anxiety Inventory (STAI) short form, which was used to measure the level of anxiety experienced by the patient before and after colonoscopy (Chan et al., 2003; Marteau \& Bekker, 1992; Van der Bij et al., 2003). The STAI short form consists of six statements regarding anxiety, being calm, tense, upset, relaxed, content, or worried. The six statements are graded on a four-point scale, from 1 to 4 , with a higher number of points indicating a higher degree of anxiety, total range from 6-24 points. The STAI short form has high reliability and acceptable validity (Marteau \& Bekker, 1992; Van der Bij et al., 2003) and was included because of its use in similar research, thus allowing the possibility of comparison with other study results.

Visual Analogue Scales (VAS), where the participants marked their answer on a line graded from 1$100 \mathrm{~mm}$, were used to measure anxiety, well-being, relaxation and pain during the colonoscopy. The patients filled out the VAS scales after the procedure and were asked to mark a line on the scales to 
indicate how they felt during the colonoscopy. The VAS scales were graded, 1-100 mm, higher values indicating a higher degree of anxiety, a higher degree of well-being, more pain and a high level of relaxation (Huskisson, 1974). The VAS for measuring pain has been tested for reliability and validity in Sweden with good results (Lundeberg et al., 2001). Also, the VAS scales used in similar studies have been found to be appropriate, and thus there was an opportunity for comparison with other research results.

\section{Data analysis}

Descriptive data are presented as percentages, numbers, mean and standard deviation. Differences between groups were assessed by the Students t-test for continuous data. Categorical data were assessed by Chi-square test and ordinal data by Mann-Whitney U test. A p-value, $p<0.05$, was regarded as statistically significant. For statistical analysis, the Statistical Package for the Social Sciences (SPSS version 17.0, Inc, Chicago, IL, USA) was used.

\section{Ethical considerations}

Permission to carry out the study was given by the Head of Department at the University hospital. The study was carried out according to the principles of the Declaration of Helsinki. According to Swedish law (2003:460) no ethical approval from the Ethics Committee is necessary when no influence on the patient is expected (Council, 2010).

\section{RESULTS}

There were 120 patients participating, of whom $36 \%$ were in the age group 31-50 years. Sixty were randomised to the intervention group listening to sedative music during colonoscopy. There was no statistical difference between the intervention and the control group regarding previous experience of colonoscopy (Table 1). 
Table 1. Characteristics of the patients in the intervention and the control groups undergoing colonoscopy.

\begin{tabular}{|c|c|c|c|c|}
\hline & $\begin{array}{l}\text { All patients } \\
n=120\end{array}$ & $\begin{array}{l}\text { Invervention group } \\
\mathrm{n}=60\end{array}$ & $\begin{array}{l}\text { Control group } \\
n=60\end{array}$ & $\begin{array}{l}\text { Intervention - } \\
\text { versus control } \\
\text { group } \\
\text { p-value }\end{array}$ \\
\hline Men/women, n, (\%) & $52(43) / 68(57)$ & $24(40) / 36(60)$ & $28(47) / 32(53)$ & 0.463 \\
\hline \multicolumn{5}{|l|}{ Age groups, n (\%) } \\
\hline $18-30$ years & $29(24)$ & $10(17)$ & $19(31)$ & $\mathrm{ns}$ \\
\hline $31-50$ years & $43(36)$ & $22(37)$ & $21(35)$ & ns \\
\hline $51-65$ years & $32(27)$ & $22(37)$ & $10(17)$ & ns \\
\hline $66-80$ years & $15(13)$ & $5 \quad(8)$ & $10(17)$ & ns \\
\hline$>80$ years & 1 & $1 \quad(1)$ & - & \\
\hline \multicolumn{5}{|l|}{ Had colonoscopy } \\
\hline previously, n (\%) & $49(42)$ & $27(46)$ & $22(37)$ & 0.352 \\
\hline
\end{tabular}


When rating the desire to listen to music during a future colonoscopy, $86 \%$ of the patients in the intervention group wanted to listen to music again compared to $67 \%$ in the control group, $\mathrm{p}=0.234$. Thirty-five percent of the patients in the intervention group wished to chose music themselves before the next colonoscopy, compared to $75 \%$ of the patients in the control group, $\mathrm{p}=0.051$.

Drugs were administered to $54(45 \%)$ of the patients. Midazolam was given to $58(48 \%)$ patients $(1.8 \pm 1.4 \mathrm{mg})$, Ketogan to $38(32 \%)$ patients $(1.4 \pm 1.5 \mathrm{mg})$ and Rapifen was given to $67(56 \%)$ patients $(0.3 \pm 0.4 \mathrm{mg})$. There was no difference in drug administration between the intervention and the control group or between men and women.

There were differences regarding anxiety, relaxation, and well-being, but no difference in experience of pain between the intervention and the control group.

Among the patients who received medication, without any significant difference in drug administration, women in the intervention group had a lower level of anxiety after the colonoscopy compared to women in the control group, $\mathrm{p}=0.007$. There were also some gender differences in anxiety (Table 2). As measured with STAI, women experienced a higher degree of anxiety before colonoscopy compared to men, $\mathrm{p}<0.0001$, especially women aged $18-30$ years, $\mathrm{p}<0.0001$, and $31-35$ years, $\mathrm{p}=0.057$. As measured with VAS, women also rated anxiety higher compared to men, $\mathrm{p}=0.004$, especially in the age group 51-65 years, $\mathrm{p}=0.027$, all without difference in analgesic or sedative medical treatment. 
Table 2. Gender differences in anxiety, relaxation, well-being and pain before and after colonoscopy.

\begin{tabular}{|c|c|c|c|}
\hline & $\begin{array}{l}\text { Men, } \mathrm{n}=52 \\
\text { md (range) }\end{array}$ & $\begin{array}{l}\text { Women, } \mathrm{n}=68 \\
\text { md (range) }\end{array}$ & p-value \\
\hline $\begin{array}{l}\text { Anxiety STAI } \\
\text { before colonoscopy, range 6-2 }\end{array}$ & $11(6-16)$ & $13(6-24)$ & $<0.0001$ \\
\hline $\begin{array}{l}\text { Anxiety STAI } \\
\text { after colonoscopy, range 6-24 }\end{array}$ & $9(6-17)$ & $9(6-24)$ & 0.924 \\
\hline $\begin{array}{l}\text { Anxiety, VAS } \\
\text { after colonoscopy, 0-100 mm }\end{array}$ & $19(0-100)$ & $32(0-97)$ & 0.004 \\
\hline $\begin{array}{l}\text { Relaxation, VAS } \\
\text { after colonoscopy, 0-100 mm }\end{array}$ & $47(0-98)$ & $50(1-100)$ & 0.745 \\
\hline $\begin{array}{l}\text { Well-being, VAS } \\
\text { after colonoscopy, 0-100 mm }\end{array}$ & $42(0-97)$ & $47(4-97)$ & 0.689 \\
\hline Pain, VAS & & & \\
\hline after colonoscopy, 0-100 mm & $38(0-88)$ & $58(2-95)$ & 0.012 \\
\hline
\end{tabular}


There was a tendency for a higher degree of relaxation among men in the intervention group compared to the men in the control group, $\mathrm{p}=0.065$, especially in the age group $31-50$ years, $\mathrm{p}=0.077$, and $51-65$ years, $\mathrm{p}=0.089$.

Well-being was significantly higher among the patients in the intervention group receiving no medication compared to the control group, $\mathrm{p}=0.006$, this was related to the men in the intervention group, $\mathrm{p}=0.025$.

Women rated pain during the colonoscopy as higher compared to men, $\mathrm{p}=0.012$, especially in the age group, 18-30 years, $\mathrm{p}=0.021$, and $51-65$ years $\mathrm{p}=0.006$, all without difference in analgesic or sedative medical treatment.

\section{DISCUSSION}

The positive effect of music during colonoscopy has previously been demonstrated in different populations (Cepeda et al., 2010; Wilson et al., 2008) but as far as we know no study has been undertaken under Swedish conditions, which is why the purpose of this study was to analyse effects of sedative music on Swedish patients' experience of anxiety, relaxation, well-being, and pain during colonoscopy.

The results of this study show that women in the intervention group experienced a higher degree of anxiety before the colonoscopy compared to men, as measured with STAI. This is congruent with results from a study by Ersöz et al (2010) who reported women to have a significantly higher state of anxiety than men prior to colonoscopy (Ersöz et al, 2010). This is also in line with earlier findings showing both men and women to be more anxious prior to a colonoscopy than they normally were (El-Hassan et al., 2009). In a randomized, controlled trial, patients who listened to self-selected music 15 minutes prior to colonoscopy reduced their anxiety level significantly more that patients who did not listen to music prior to the colonoscopy (Haynes et al 2003). Anxiety 
prior to colonoscopy may be explained by different reasons, such as anxiety that the procedure may be painful as well as concern related to the result of the colonoscopy, since this result might lead to a diagnosis that in turn could cause anxiety. Women in the intervention group had a lower level of anxiety after the colonoscopy compared to women in the control group, which is supported by other studies showing a reduction of anxiety after listening to music during colonoscopy (Costa et al., 2010; El-Hassan et al., 2009; Ovayolu et al., 2006; Wilson et al., 2008). This is a reason for nurses to offer patients the simple intervention of listening to music both prior to and during colonoscopy.

There was a tendency for a higher degree of relaxation among men in the intervention group compared to the men in the control group. No studies on gender differences were found, but patients' overall experience was improved in the group listening to music as reported by a metaanalysis of eight randomised controlled studies on patients undergoing colonoscopy (Bechtold et al., 2009) as was satisfaction among patients in the music groups in two further studies of colonoscopy patients (Costa et al., 2010; El-Hassan et al., 2009). Relaxation, overall experience, and satisfaction are very closely related to the experience of well-being, which in the subgroup analysis was revealed to be higher among men in the intervention group who had not had any drugs administered. Altogether, this gives a clear indication of the efficacy of music in reducing discomfort during colonoscopy, which is supported by several other studies (Bechtold et al., 2009; Costa et al., 2010; Leung, 2008; Ovayolu et al., 2006).

One might expect that the relaxation and well-being that was higher among men in the intervention group was influenced by experience of pain; however, in this study no difference was found regarding the experience of pain between the intervention and the control groups. These findings are consistent with findings of Bechtold et al (2009) (Bechtold et al., 2009) who in their review of eight randomised controlled trials did not find any significant differences regarding experience of pain between patients listening to music or those in the control group. Similar findings were 
reported by Wilson et al (2008) (Wilson et al., 2008) in their review of eight studies, where weak evidence of the influence of music on experience of pain was found. However, in their review of five studies Cepeda et al (2010) (Cepeda et al., 2010), found the discomfort of painful procedures was eased by listening to music. These opposite findings could not be explained by the use of sedative or analgesic treatment as no differences between the intervention and control groups were reported regarding drug administration in the current study.

Women experienced a higher degree of pain during the colonoscopy compared to men, which is similar to findings in an Italian study where women gave higher pain scores compared to men during colonoscopy (Costa et al., 2010). Ylinen et al, (2009) likewise reported that women who were not offered the opportunity to listen to music during colonoscopy also rated pain level significantly higher compared to men (Ylinen et al, 2009). This might be important to consider when caring for women during colonoscopy as they, due to both experience of anxiety and pain, may need more medical treatment than they usually receive, in addition to listening to music.

Men in this study who listened to sedative instrumental music were reported to feel relaxed, which may be considered in the future when offering patients the opportunity to listen to music. Thirtyfive percent of the patients in the intervention group also wanted to choose music themselves before their next colonoscopy. Whether patients' own choice of music or a certain type of music should be selected for a certain therapeutic procedure or clinical situation has not yet been clarified (Thoorgard et al., 2005), but is important to consider in future studies.

In this study, a CD-player with earphones was used, which in the future may be replaced by digital music players or MP3 players that can store a large amount of different music. This means that the choice of music can be increased and the music genre can be changed easily. Although it involves the use of technology, using music is cheap to offer and no harmful effects have been reported 
(Wilson et al., 2008).

One limit of this study is that its demographic data is limited, which might have reduced the possibilities for analysis. Another limit with this study design is that ages were split up into five age groups, which also might reduce the analysis options. Furthermore, no objective data was collected, which might reduce comparability with the results of other studies.

\section{CLINICAL IMPLICATIONS}

As there still is no clear clinical evidence for the effectiveness of the use of music prior to and during colonoscopy, nurses should consider asking outpatients if they want to listen to music at these times. The best practice may be to offer the opportunity to listen to music in the invitation letter to the endoscopy department. This would give the patients the chance to bring their own choice of music. Patients undergoing colonoscopy during a stay in a hospital ward should also be offered the opportunity to listen to music during the colonoscopy as they must be presumed to experience similar levels of anxiety as outpatients.

It is a great challenge to pay attention to patients' degree of anxiety and individually adapt the nursing care accordingly. In the future it will be necessary to further study the effect of music during colonoscopy in randomized controlled studies with large samples. Preferably, patients should bring their own music, and the effects of different types of music could then be analysed.

\section{CONCLUSION}

Listening to sedative music decreased anxiety among women and increased well-being among men during colonoscopy. This simple procedure, which improves well-being, should be offered to every patient prior to colonoscopy. 


\section{CONFLICT OF INTEREST}

There is no conflict of interest in this study.

\section{REFERENCES}

Bechtold, M., Puli, S., Othman, M., Bartalos, C., Marshall, J. \& Roy, P. (2009): Effect of music on patients undergoing colonoscopy: a meta-analysis of randomized controlled trials. Dig Dis Sci, 1, 19-24.

Bonny, H. (1986): Music and healing. Music Ther, 6, 3-12.

Bringman, H., Giesecke, K., Thörne, A. \& Bringman, S. (2009): Relaxing music as premedication before surgery: a randomized controlled trial. Acta Anesthesiol Scand, 53, 759-764.

Carlisle, S., Henderson, G. \& Hanlon, P. (2009): Wellbeing: A collateral casualty of modernity? Soc Sci \& Med, 1556-1560.

Cepeda, M., Carr, D., Lau, J. \& Alvarez, H. (2010): Music for pain relief. The Cochrane Library.

Chan, Y., Lee, P., Ng, T., Ngan, H. \& Wong, L. (2003): The use of music to reduce anxiety for patients undergoing colposcopy: an randomized trial. Gynegol Oncol, 91, 213-217.

Costa, A., Montalbano, L., Orlando, A., Ingoglia, C., Linea, C., Giunta, M., Mancuso, A., Mocciaro, F., Bellingardo, R., Tine`, F. \& D’Amico, G. (2010): music for colonoscopy: A single-blind randomized controlled trial. Dig and Liver Disease, 42(12), 871-876.

Council T.S.R. (2010) Rules and guidelines for research. http://www.codex.uu.se/en/index.shtml, Stockholm.

El-Hassan, H., McKeown, K. \& Muller, F. (2009): Clinical trial: music reduces anxiety levels in patients attending for endoscopy. Aliment Pharmacol Ther, 718-724.

Engwall, M. \& Sörensen Duppils, G. (2009): Music as a nursing intervention for postoperative pain: A systematic review. J Perianesth Nurs 24, 370-383.

Harikumar, R., Raj, M., Paul, A., Harish, K., Kumar, S., Sandesh, K., Asharaf, S. \& Thomas, V. (2006): Listening to music decreases need for sedative medication during colonoscopy: a randomized controlled trial. Indian J Gastroenterol, 1, 3-5.

Huskisson, E. (1974): Measurement of pain. Lancet, 2, 1127-1131.

Johnson, D. \& Speigelberg, C. (1968): The effects of relaxation training and the passage of time on measures of state- and trait-anxiety. J Clin Psychol, 1, 20-23.

Keifer, R. (2008): An integrative review of the concept of well-being. Holist Nurs Pract, 5, 244252.

Leung, F. (2008): Methods of reducing discomfort during colonoscopy. Dig Dis Sci, 1462-1467.

Lundeberg, T., Lund, I., Dahlin, L., Borg, E., Gustafsson, C., Sandin, L., Rosén, A., Kowalski, J. \& Eriksson, S. (2001): Reliability and responsiveness of three different pain assessments. J Rehabil Med, 33, 297-283.

Marteau, T. \& Bekker, H. (1992): The development of a six-item short-form of the state scale of the Spiegelberger State-Trait Anxiety Inventory (STAI). Br J Clin Psychol, 31, 301306.

Mersky, H. \& Bogduk, N. (1994) Classification of chronic pain. IASP Press. Seattle.

Messman, H. \& Barnet, J. (2006) Atlas of colonoscopy examination techniques and diagnosis. Thieme, New York.

Miluk-Kolasa, B., Matejek, M. \& Stupnicki, R. (1996): The effect of music listening on changes in selected physiological parameters in adult pre-surgical patients. Journal of Music Therapy, 33, 208-218.

Miluk-Kolasa, B., Obminski, Z., Stupnicki, R. \& Golec, L. (1994): Effects of music treatment 
on salivary cortisol in patients exposed to pre-surgical stress. Experimental and Clinical Endocrinology, 102, 118-120.

Nguyen, T., Nilsson, S., Hellström, A. \& Bengtsson, A. (2010): Music therapy to reduce pain and anxiety in children with cancer undergoing lumbar puncture: A randomized clinical trial. J Pediatr Onc Nurs, 27, 146-155.

Nilsson, S., Kokinsky, E., Nilsson, U., Sidenvall, B. \& Enskär, K. (2009): School-aged children's experience of postoperative music medicine on pain, distress, and anxiety. Pediatr Anesthesia, 19, 1184-1190.

Nilsson, U. (2008): The anxiety and pain reducing effects of music interventions: A systematic review. AORN, 87, 780-807.

Ovayolu, N., Ucan, O., Pehlivan, S., Pehlivan, Y., Buyukhatipoglu, H., Savas, M. \& Gulsen, M. (2006): Listening to Turkish classical music decreases patients' anxiety, pain, dissatisfaction and the dose of sedative and analgesic drugs during colonoscopy: A prospective randomized controlled trial. Wourld J Gastroenterol, 46, 7532-7536.

Smolen, D., Topp, R. \& Singer, L. (2002): The effect of self-selected music during colonoscopy an anxiety, heart rate, and blood pressure. Appl Nurs Res, 3, 126-136.

Thoorgard, P., Ertmann, E., Hansen, V., Noerregaard, A., Hansen, V. \& Spanggaard, L. (2005): Designed sound and music environment in postanaesthesia care units - a multicentre study of patients and staff. Int Crit Care Nurs, 220-225.

Van der Bij, A., de Weerd, S., Cikot, R., Steegers, E. \& Braspenning, J. (2003): Validation of the Dutch short form of the state scale of Spiegelberger State-Trait Anxiety Inventory: considerations for usage in screening outcomes. Community Genet, 6, 84-87.

Vanderboom, T. (2007): Does music reduce anxiety during invasive procedures with procedural sedation? An integrative research review. J Radiol Nurs, 1, 15-22.

WHO (2006) Facts Sheets, Cancer, WHO 2006. www.who.int/mediacentre/factsheets/fs297/en/index.html.

Wilson, W., Wong, E. \& Twinn, S. (2008): Effect of music on procedure time and sedation during colonoscopy: A meta-analysis. World J Gastroenterol, 34, 5336-5343.

Ylinen, E., Vehviläinen-Julkunen, K. \& Pietilä, A. (2007): Nurses' knowledge and skills in colonoscopy patients' pain management. J Clin Nurs, 6, 1125-1133. 